Plant Tissue Cult. \& Biotech. 22(1): 33-39, 2012 (June)

\title{
Rapid and Efficient Plant Regeneration from Nodal Explants of Artemisia annua L.
}

\author{
B. Janarthanam, P. Rashmi ${ }^{1}$ and E. Sumathi* \\ Omnigreen Organic Biopark Pvt. Ltd., Plant Biotechnology Division, lwarthirunagar, \\ Chennai- 600 087, Tamil Nadu, India
}

Key words: Artemisia annua, Plant regeneration, Nodal explant, Mass propagation

\begin{abstract}
An efficient plant regeneration protocol was developed for Artemisia annua, an aromatic medicinal herb. Nodal explants inoculated on MS supplemented with $4.44 \mu \mathrm{M}$ BAP showed better growth response and produced $116.2 \pm 0.1$ microshoots of an average length $1.9 \pm 0.3 \mathrm{~cm}$ after 35 days culture. The cluster of small shootlets were cultured on shoot elongation medium supplemented with 1.44 $\mu \mathrm{M} \mathrm{GA} 3$ and $10 \%$ coconut milk (CM) showed shoot elongation up to $4.6 \pm 0.7 \mathrm{~cm}$. Roots were induced after transfer to half strength MS supplemented with 2.46 $\mu \mathrm{M}$ IBA produced $14.3 \pm 0.2$ roots with an average height of $4.3 \pm 0.53 \mathrm{~cm}$ after 30 days. The rooted plantlets were transferred for hardening, 80 per cent of plantlets survived and resumed growth in the mixture of soil, vermiculite and farm yard manure $(1: 1: 1)$.
\end{abstract}

\section{Introduction}

Artemisia annua L. a valuable medicinal plant belongs to Asteraceae. It is grown commercially in many parts of Europe, America, China, Turkey, Iran, Afghanistan and Australia (Bhakuni et al. 2001, Allen et al. 1997). In India, it is being cultivated on an experimental basis in temperate as well as subtropical conditions (Mathur and Kumar 1996, Prasad et al. 1997, Ram et al. 1997). All Artemisia species produce aromatic oils and important compounds, such as artemisinin produced by Artemisia annua, very effective against both Plasmodium vivax and Plasmodium falciparum, the latter being responsible for cerebral malaria (Klayman 1985, Sy and Brown 2001). Artemisinin is a rare sesquiterpene lactones end peroxide isolated from $A$. аnnua, it was recommended as a medicine against malaria. The yield of the active compound from wild or cultivated plants (leaves

*Author for correspondence: Department of Biotechnology, D.G. Vaishnav College, University of Madras, Arumbakkam, Chennai-600106, Tamil Nadu, India. <sumathiethiraj@yahoo.com>. ${ }^{1}$ Department of Microbiology, Valliammal College for Women, E-9, Anna Nagar East, Chennai - 600 102, Tamil Nadu, India. 
or flower) is low and varies from 0.01 to $0.06 \%$ but may reach $0.5 \%$ in certain Chinese varieties (Klayman 1985, Ferreira et al. 1997). Populations raised from seeds are characterised by morphological variation in plant height, leaf biomass and flowering dates, thus, resulting in low and variable yield of the active constituents (Elhag et al. 1992). Micropropagation and organogenesis of different Artemisia species have been previously established by using several parts of plants, in order to obtain a large number of plants, such as A. scorpia (Aslam et al. 2006), A. vulgaris L. (Govindaraj et al. 2008), A. mutellina Vill. (Mazzetti and Donato 1998). In vitro culture of $A$. annua has been attempted through organogenesis (Lualon et al. 2008). The present study aims at developing a simple, rapid, economical, and high frequency regeneration protocol from nodal explants of $A$. annua for potential application in large scale propagation.

\section{Material and Methods}

Healthy plants of Artemisia annua L. collected from Ooty Botanical Garden (Ooty), Tamil Nadu, India and were raised in pots containing soil and farm yard manure $(1: 1)$ under greenhouse conditions at Department of Biotechnology of authors' College. Nodal segments were collected from potted plants, brought to the laboratory and processed. For surface sterilization, the explant were cleaned thoroughly under running tap water for $20 \mathrm{~min}$; washed with a solution of Tween 20 ( 2 drops in $100 \mathrm{ml}$ of water) for $1 \mathrm{~min}$, and again washed with sterile distilled water. The cleaned explants were finally treated with $0.1 \%(\mathrm{w} / \mathrm{v}) \mathrm{HgCl}_{2}$ for 4 min under aseptic conditions and washed five times with sterile distilled water to remove traces of $\mathrm{HgCl}_{2}$.

After surface sterilization, explants were trimmed to $0.8-1.0 \mathrm{~cm}$ and inoculated on MS supplemented with individual concentrations of BAP (1.11, $2.22,4.44,6.66$ and $8.88 \mu \mathrm{M})$, TDZ $(1.14,2.27,4.54,6.77$ and $9.08 \mu \mathrm{M})$ and $\mathrm{Kn}(0.46$, 2.32, 4.65, 9.20 and $13.75 \mu \mathrm{M})$ for shoot multiplication. At the end of the experiment, percentage of shooting, shoot length and the number of shoots per explant were recorded after 35 days in culture. Small shoots were transferred to MS supplemented with different concentrations of $\mathrm{GA}_{3}(0.72-2.89 \mu \mathrm{M})$ with $\mathrm{CM}$ $(10.0 \%)$ for shoot elongation.

The proliferated shootlets $(4.6 \mathrm{~cm}$ in length) were excised from cultures and transferred to half strength MS supplemented with IBA $(0.49,0.98,2.46,4.92$ and $12.30 \mu \mathrm{M})$ for in vitro rooting. Root number and length were recorded after 30 days in culture. Well developed plantlets were rinsed thoroughly with sterile water to remove residuals and potted with a mixture of red soil, vermiculite and farm yard manure $(1: 1: 1)$, covered with transparent polyethylene bags to 
ensure high humidity. After 15 days, the fully acclimatized plantlets were transplanted to plastic pots ( $80 \mathrm{~mm}$ diameter).

For all the above studies, MS supplemented with $3 \%(\mathrm{w} / \mathrm{v})$ sucrose was used for all in vitro culture studies. The $\mathrm{pH}$ of the medium was adjusted to $5.6 \pm 0.2$ prior to adding $0.9 \%(\mathrm{w} / \mathrm{v})$ agar, and autoclaved at $121^{\circ} \mathrm{C}$ for $15 \mathrm{~min}$. Cultures were maintained at $25 \pm 1^{\circ} \mathrm{C}$ under $16 \mathrm{hr}$ photoperiod with a photosynthetic photon flux density (PPFD) of $50 \mu \mathrm{mol} \mathrm{m} \mathrm{m}^{-2} \mathrm{~s}^{-2}$ provided by cool white fluorescent tubes (Phillips, India) and with $60-65 \%$ relative humidity. The plant growth regulators (PGRs) were filter sterilized using $0.2 \mu \mathrm{m}$ filter (Minisart巴, Sartorius,VivaScience AG, Hannover, Germany) prior to addition to culture media.

Each experiment was repeated three times and each treatment had six replicates. The data were analysed using ANOVA, and the means were compared using the DMRT using SPSS (SPSS version 16.0) at $5 \%$ level of significance $(\mathrm{p}<0.05)$.

\section{Results and Discussion}

Multiple shoots developed from nodal explants cultured on MS supplemented with BAP $(1.11$ - $8.88 \mu \mathrm{M})$, TDZ $(1.14-9.08 \mu \mathrm{M})$ and $\mathrm{Kn}(0.46-13.75 \mu \mathrm{M})$. In the present study, individual concentration of BAP seems to influence the induction of shoots in Artemisia annua. Initiation of multiple shoots in most of the treatments was observed within three weeks of culture. High number of microshoots developed in MS containing 4.44 $\mu \mathrm{M}$ BAP showed better growth response $(80 \%)$ and produced $116.2 \pm 0.1$ small shootlets per explant with an average length of $1.9 \pm 0.3 \mathrm{~cm}$ after 35 days of culture (Table 1, Fig. 1A-C). The cluster of small shootlets were cultured on shoot elongation medium supplemented with $1.44 \mu \mathrm{M} \mathrm{GA} 3$ and $10 \% \mathrm{CM}$ showed shoot elongation up to $4.6 \pm 0.4 \mathrm{~cm}$ (Table 2, Fig. 1D).

Higher concentration of BAP $(8.88 \mu \mathrm{M})$ resulted in gradual decrease in the number of shoots per explants. BAP has been considered to be one of the most active cytokinins in organogenic differentiation in plant tissue culture (Gururaj et al. 2007, Fracaro and Echeverrigaray 2004, Janarthanam et al. 2009). Coconut milk $(\mathrm{CM})$ is an undefined complex mixture of organic substances that has been successfully employed for culturing different plant species (Arditti and Ernst 1993, Suttle 1996, Janarthanam et al. 2011). It is evident in their report that CM stimulated the development of shoot buds. In general, CM is known to promote callus formation and also plays a suppressive role in the formation of shoots buds. However, in the present investigation the results were contrary to the general trends and coincided with the findings of Maity et al. 2005. Nodal 
explants transferred to MS containing TDZ $(1.14-9.08 \mu \mathrm{M})$, TDZ $4.54 \mu \mathrm{M}$ produced 17 small shoots and an average length of $1.7 \mathrm{~cm}$ after 35 days, whereas the higher concentration of TDZ $(9.08 \mu \mathrm{M})$ produced dark green callus and compact structures which ultimately turned brown and failed to develop into normal shoots (Table 1$)$. In KN alone $(0.46-9.20 \mu \mathrm{M})$ supplemented medium was not effective.
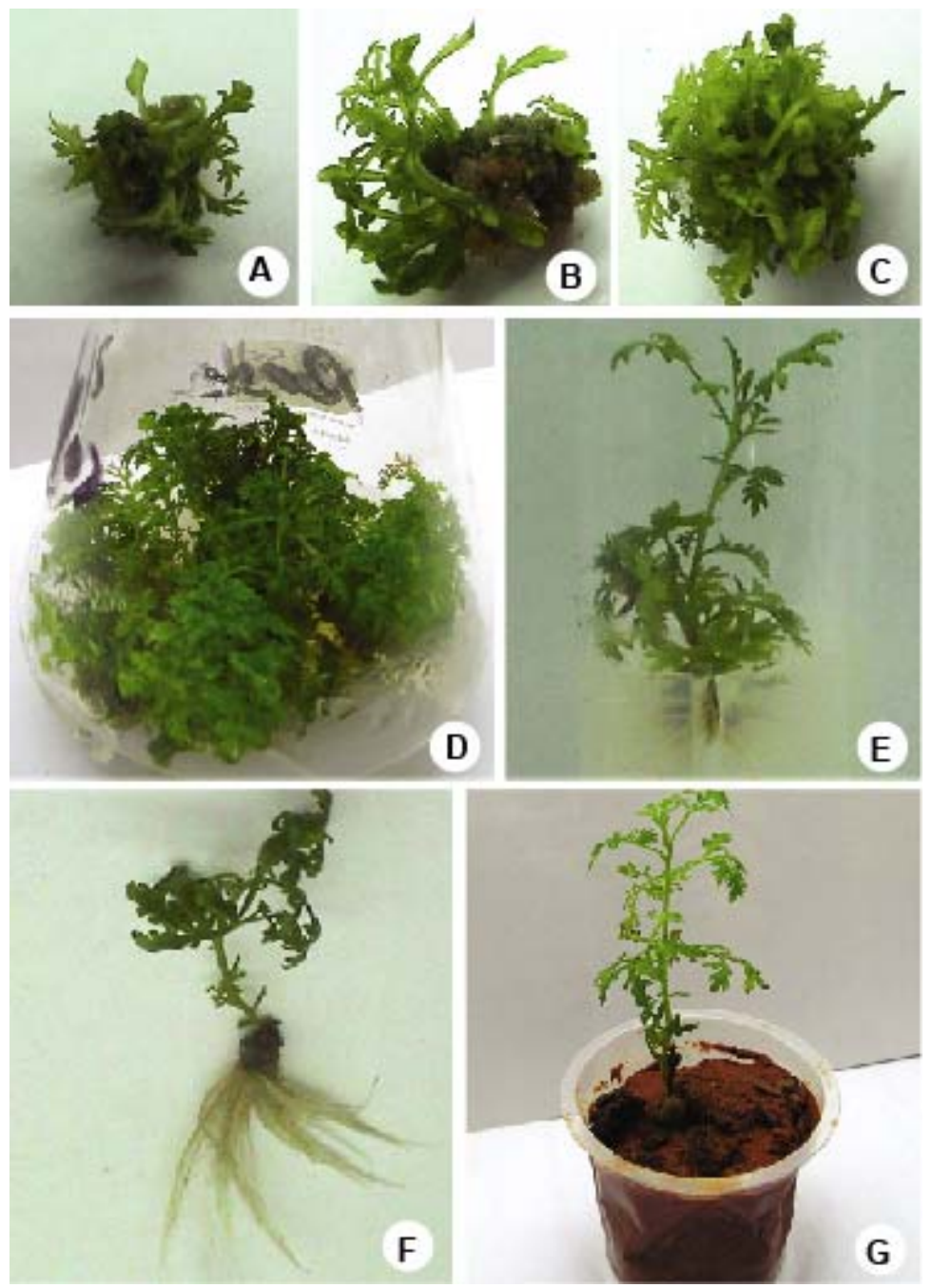

Fig 1. A-F. Regeneration of multiple shoot from nodal explants of Artemisia annua. A-B. Nodal explants inoculated on MS supplemented with BAP $4.44 \mu \mathrm{M}$ after two weeks of culture. C. Proliferation of multiple shoots from nodal explants at 35 days of cultured on MS containing BAP $4.44 \mu \mathrm{M}$. D. Cluster of small shootlets were cultured on shoot elongation medium supplemented with $1.44 \mu \mathrm{M} \mathrm{GA}_{3}$ and $10 \% \mathrm{CM}$. E. Healthy in vitro shootlets inoculated on half strength MS containing 2.46 $\mu \mathrm{M}$ IBA. F. A well established plant. G. Well established and hardened in vitro plants successfully transferred to the paper cups. 
Table 1. Effect of BAP on shoot regeneration from nodal explants of Artemisia annua.

\begin{tabular}{ccccc}
\hline $\begin{array}{l}\text { Growth regulators } \\
(\mu \mathrm{M})\end{array}$ & $\begin{array}{c}\text { Response } \\
(\%)\end{array}$ & $\begin{array}{c}\text { Number of shoot } \\
\text { per explant }\end{array}$ & $\begin{array}{c}\text { Shoot length } \\
(\mathrm{cm})\end{array}$ \\
\hline BAP & 1.11 & $39.8 \pm 2.9$ & $17.6 \pm 0.4$ & $1.2 \pm 0.3$ \\
& 2.22 & $46.8 \pm 3.5$ & $24.0 \pm 2.1$ & $1.3 \pm 0.1$ \\
& 4.44 & $80.0 \pm 5.0$ & $116.2 \pm 0.1$ & $1.9 \pm 0.3$ \\
& 8.88 & $52.8 \pm 3.9$ & $29.1 \pm 0.4$ & $1.1 \pm 0.1$ \\
$\mathrm{TDZ}$ & 2.27 & $34.9 \pm 3.2$ & $14.2 \pm 2.8$ & $1.1 \pm 0.2$ \\
& 4.54 & $40.0 \pm 2.5$ & $17.1 \pm 1.1$ & $1.7 \pm 0.2$ \\
& 6.77 & $37.7 \pm 4.6$ & $16.5 \pm 2.3$ & $1.4 \pm 0.5$ \\
& 9.08 & $28.6 \pm 3.3$ & $11.9 \pm 1.3$ & $1.3 \pm 0.3$ \\
$\mathrm{Kn}$ & 0.46 & $8.6 \pm 0.8$ & $4.3 \pm 1.0$ & $1.1 \pm 0.1$ \\
& 2.32 & $15.9 \pm 3.3$ & $6.1 \pm 1.6$ & $1.3 \pm 0.1$ \\
& 4.65 & $23.9 \pm 2.9$ & $10.3 \pm 1.6$ & $1.4 \pm 0.1$ \\
& 9.20 & $5.3 \pm 6.9$ & $2.0 \pm 1.4$ & $1.0 \pm 0.3$ \\
\hline
\end{tabular}

Results represent mean \pm SD of three replicated experiments and data were recorded after 35 days of culture.

Table 2. Effect of different concentrations of $\mathrm{GA}_{3}$ and $\mathrm{CM}$ on $\mathrm{MS}$ on shoot elongation from in vitro microshoot of Artemisia annua.

\begin{tabular}{lcll}
\hline $\begin{array}{l}\text { Growth regulators } \\
\mathrm{GA}_{3}(\mu \mathrm{M})\end{array}$ & $\begin{array}{l}\text { Concentration of } \\
\mathrm{CM}(\%)\end{array}$ & $\begin{array}{l}\text { Mean number of } \\
\text { shoots/explant }\end{array}$ & $\begin{array}{l}\text { Mean shoot } \\
\text { length }\end{array}$ \\
\hline Control & & $116.2 \pm 0.1$ & $1.9 \pm 0.3$ \\
0.72 & 5 & $116.2 \pm 0.1$ & $1.9 \pm 0.3$ \\
& 10 & $116.2 \pm 0.1$ & $2.3 \pm 0.3$ \\
& 15 & $116.2 \pm 0.1$ & $2.0 \pm 0.2$ \\
1.44 & 5 & $116.2 \pm 0.1$ & $3.1 \pm 0.3$ \\
& 10 & $116.2 \pm 0.1$ & $4.6 \pm 0.4$ \\
2.89 & 15 & $116.2 \pm 0.1$ & $3.4 \pm 0.5$ \\
& 5 & $116.2 \pm 0.1$ & $2.2 \pm 0.2$ \\
& 10 & $116.2 \pm 0.1$ & $2.8 \pm 0.5$ \\
& 15 & $116.2 \pm 0.1$ & $2.3 \pm 0.2$ \\
\hline
\end{tabular}

Control: MS with BAP $1.0 \mathrm{mg} / \mathrm{l}$. Results represent mean $\pm \mathrm{SD}$ of three replicated experiments. Data were recorded after 35 days of culture.

Individual shoots from a multiple shoot complex were separated after 28 days of culture and transferred to half strength of MS supplemented with IBA $(0.49-12.30 \mu \mathrm{M})$. The root induction was initiated after two weeks of culture, and after four week s, the root system was well developed (Fig. 1E,F). The 
maximum rooting response $(75 \%)$ was achieved on medium supplemented with IBA $(2.46 \mu \mathrm{M})$, with an average of 14 roots per in vitro shoot (Table 3$)$. Higher concentration of IBA $(12.30 \mu \mathrm{M})$ resulted in gradual decrease in the number of shoots per explants.

Table 3. Effect of different concentration of IBA in half strength MS on rooting response of Artemisia annua.

\begin{tabular}{lccc}
\hline IBA $(\mu \mathrm{M})$ & \% response & Roots/shoot & Root length $(\mathrm{cm})$ \\
\hline 0.49 & $30.0 \pm 5.0$ & $2.6 \pm 0.5$ & $3.06 \pm 0.3$ \\
0.98 & $31.6 \pm 2.8$ & $2.6 \pm 1.2$ & $3.06 \pm 0.5$ \\
2.46 & $75.0 \pm 5.0$ & $14.3 \pm 0.2$ & $4.3 \pm 0.53$ \\
4.92 & $45.0 \pm 5.0$ & $2.6 \pm 0.6$ & $2.30 \pm 0.3$ \\
12.30 & $36.6 \pm 2.8$ & $2.0 \pm 1.0$ & $2.00 \pm 0.2$ \\
\hline
\end{tabular}

Results represent mean \pm SD of three replicated experiments and data were recorded after 30 days of culture.

In the present study root induction was obtained with lower concentration of IBA $2.46 \mu \mathrm{M}$ and produced significantly higher rooting this could be attributed to the nature of in vitro shootlets from nodal explants grown on BAP. Eighty percent plantlet survival was seen after hardening of the regenerated Artemisia annua in red soil, vermiculite and farmyard manure $(1: 1: 1)$ for three weeks. However, the rate decreased as some plants died over the next 4-5 weeks after transfer to soil. It was observed that very gradual acclimatization of in vitro grown plants to the external environment is most essential to Artemisia annua. Seventy per cent of the plants transferred to pots survived and resumed growth (Fig. 1G).

In conclusion, the results showed the ability of the internodal explant explants to produce higher number of shootlets without any intervening callus phase, where all the plantlets were uniform in height and growth. Hence, the present authors propose this protocol a simple, economical, rapid and highly reproducible to obtain more plantlets within a short period of time.

\section{References}

Allen PC, lydon J and Danforth HD (1997) Effects of components of Artemisia annua on coccidian infections in chickens. Poultry Sci. 76: 1156-1163.

Arditti J and Ernst R (1993) Micropropagation of orchids. John Wiley, New York. 38-39.

Aslam N, Zia M and Chaudhary M F (2006) Callogenesis and Direct Organogenesis of Artemisia scoparia, Pakistan Journal of Biological Science. 9: 1783-1783.

Bhakuni RS, Jain DC, Sharma RP and Kumar S (2001) Secondary metabolites of Artemisia annua and their biological activity. Current Science. 80: 35-48. 
Elhag H, El-Feraly F, Mossa JS and Hafez M (1992) In vitro micropropagation of Artemisia annua L. J. king Saud Univ. 3: 251-259.

Ferreira JFS, Simon JE and Janick J (1997) Developmental studies of Artemisia annua L.: flowering and artemisinin production under greenhouse and field conditions. Planta Med. 61: 167-170.

Fracaro F and Echeverrigaray S (2004) Micropropagationof Cunila galioides, a popular medicinal plant of south Brazil. Plant Cell, Tiss and Organ Cult. 64: 1-4.

Govindaraj S, Kumary BD, Gioni PL and Flamini G (2008) Mass Propagation and Essential Oil Analysis of Artemisia vulgaris, J. of Bioscience and Bioengineering. 105: 176-183.

Gururaj HB, Giridhar P and Ravishankar GA (2007) Micropropagation of Tinospora cordifolia (Willd.) Miers ex Hook.F \& Thoms - a multipurpose medicinal plant. Curr. Scie. 9: 23-26.

Janarthanam B, Gayathri B and Sumathi E (2011) A Rapid, High Frequency Regeneration of Justicia gendarussa Burm.f. Bangladesh J. Sci. Ind. Res. 46: 201-204.

Janarthanam B, Gopalakrishnan M and Sekar T (2009) In vitro shoot regeneration from nodal explants of Exacum travancoricum. J. Trop. Med. Plants. 10: 205-208.

Klayman D L (1985) Qinghazu (artemisinin): an ant malarial drug from China. Science. 228: 1049- 1055.

Lualon W, De-Eknamkul W, Tanaka H Shoyama Y Putalun W (2008) Artemisinin production by shoot regeneration of Artemisia annua L. using thidiazuron. Z Naturforsch [C]. 63: 96-100.

Maity S, Ray S and Banerjee N (2005) The role of plant growth regulators on direct and in direct plant re generation from various organs of Leucaena leucocephala. Acta Physiol. Plant. 27: 473-480.

Mathur AK and Kumar S (1996) Micropropagation of Artemisia annua via the inflorescence Journal of Herbs, Spices \& Medicinal Plants, 4 : 61-71.

Mazzetti C and Donata M (1998) Micropropagation of Artemisia mutellina, ISHS Acta Horticulturae 457; Symposium on Plant Biotechnology as a tool for the exploitation of Mountain Lands.

Prasad D, Kumar D, Anuwar M, Singh DV and Jain DC (1997) Response of Artemisia annua L. of soil salinity . J. Herbs Spices Med. Plants. 5: 49-55.

Ram M, Gupta MM, Dwivedi S and Kumar S (1997) Effect of plant density on the yields of artemisinin and essential oil in Artemisia annua cropped under low input cost management in north-central India. Planta Med. 63: 372-374.

Suttle GRL (1996) Commercial laboratory production. In: Plant tissue culture concepts and laboratory exercises, ed. by Trigiano, R.N., Gray, D.J. - CRC Press, Inc. New York: 331-339.

Sy L and Brown GD (2001). Deoxyarteannium B, dihydrodeoxyteannium B and trans-5hydroxyl-2-isoprenyl-5-methyl hex - 3en - ol from Artemisia annua. Pythochememistry. 58: 1159-1166. 